\title{
HÁBITOS DE HIGIENE Y MANTENIMIENTO DE CEPILLO DENTAL ANTES Y DESPUÉS DE LA APLICACIÓN DE UN MATERIAL EDUCATIVO
}

\author{
${ }^{1}$ Lizeth Tatiana Arias Ayala, ${ }^{1}$ Victor Manuel Hernández Suárez, ${ }^{2}$ Gloria Cristina Aránzazu Moya, \\ ${ }^{3}$ Carmen Alodia Martínez López. \\ ${ }^{1}$ Estudiante de $\mathrm{X}$ semestre F. de Odontología U. Santo Tomás. ${ }^{2}$ Odontóloga \\ U. Santo Tomás, Especialista en Patología Oral y Medios Diagnósticos
}

U. El Bosque, Docente U. Santo Tomás. ${ }^{3}$ Licenciada en Ciencias de la Educación Química y Biológica UPTC, Odontóloga U. Santo Tomás, Especialista en Ortopedia Maxilar U. Antonio Nariño, Docente U. Santo Tomás.

Autor responsable de correspondencia: Gloria Cristina Aránzazu M.

Correo electrónico: gloriacristina33@mail.ustabuca.edu.co

\section{RESUMEN}

Objetivo: Evaluar los aspectos relacionados con el almacenamiento y el mantenimiento del cepillo dental, antes y después aplicar un material educativo.

Materiales y métodos: Se realizó un ensayo clínico controlado en 100 pacientes asignados al azar, se evaluaron variables sociodemográficas, de conocimiento, de uso, higiene y almacenamiento del cepillo dental antes y después de aplicar un material educativo. Para el análisis estadístico se aplicaron medidas de resumen, chi², test exacto de Fisher según la distribución de los datos. Se considero un nivel de significancia de $\alpha: 0.05$.

Resultados: Se observó que la frecuencia de uso diario de cepillo dental del total de la población fue de 2.9 veces al día, realizaban recambio de cepillo cada 5.4 meses. Después de realizada la aplicación del material educativo, se encontró que de los pacientes que guardaban el cepillo en forma individual, el $70.2 \%$ correspondió al grupo intervenido $(p=0.001)$ frente al $30 \%$ del grupo no intervenido. Respecto al uso de desinfección, del $1 \%$ paso al $26 \%$ después de la intevencion ( $\mathrm{p}<0.001$ ). Al finalizar el estudio, se observo que el $50 \%$ de los cepillos no tenían placa y de éstos, el 66\% correspondió al grupo intervenido ( $\mathrm{p}=0.001$ ).

Conclusión: El material educativo generó cambios en el mantenimiento de los cepillos dentales en la población estudiada. [Arias LT, Hernández VM, Aránzazu GC, Martínez CE. Hábitos de higiene y mantenimiento del cepillo dental antes y después de la aplicación de un material educativo. Ustasalud 2009; 8: 37 - 43]

Palabras clave: Cepillos dentales, Almacenamiento, Desinfección.

\section{HABITS OF HYGIENE AND MAINTENANCE OF TOOTHBRUSH BEFORE AND AFTER THE APPLICATION OF AN EDUCATIVE MATERIAL}

\begin{abstract}
Objective: To evaluate the aspects related to storage and maintenance of the toothbrush, before and after applying an educational material.

Methods: A controlled clinical trial in 100 randomized patients was done. The following variables were analyzed: demographic characteristics, knowledge, usage and storage of the toothbrush before and after applying an educative material. Means, modes, medians and standard deviation were determined for all data. Bivariate analyses were performed by Student's t test and Fisher Exact test. For all tests, $\mathrm{p} \leq 0.05$ was considered statistically significant.

Results: The frequency of daily use of toothbrush of the total population was 2.9 times per day, the toothbrush was replaced every 5.4 months. After applying the educational material, $70,2 \%$ (experimental group) kept individually the toothbrush ( $\mathrm{p}=0.001)$ compared with $30 \%$ in the control group. At the end of the study, $50 \%$ of the toothbrush had no dental plaque; out of these $50 \%$ mentioned before, $66 \%$ were in the experimental group $(\mathrm{p}=0.001)$.

Conclusion: The educational material produced changes in the maintenance of toothbrushes in the study population.
\end{abstract}

Key words: Toothbrush, Storage, Disinfection, Maintenance.

Recibido para publicación: 12 de mayo de 2009. Aceptado para publicación: 30 de junio de 2009 


\section{INTRODUCCIÓN}

En los últimos años se han realizado varios estudios que reflejan la relación que tiene el cepillo dental con enfermedades bucales ya que las bacterias al depositarse entre las cerdas de éste, se incuban, se reproducen y desecadenan infecciones repetitivas en los individuos. ${ }^{1}$ Los microorganismos causantes de diferentes enfermedades de la cavidad bucal, al no encontrarse de forma libre en el medio ambiente requieren de un huésped el cual puede hacer transferencia de los mismos a otros hospederos donde pueden colonizar y producir enfermedad. ${ }^{1,2}$

La presencia de microorganismos en los cepillos dentales ha sido evidenciada en numerosos estudios que afirman que este implemento ofrece la ventaja de realizar una muy buena remoción de los depósitos de placa bacteriana de las superficies dentales, siendo el más utilizado en el mundo para este fin. Sin embargo, brinda la desventaja de convertirse en un vector de agentes causantes de caries dental, gingivitis y periodontitis agresiva o severa, y contribuye a la diseminación sistémica de microorganismos. ${ }^{1-3}$ Así se ha demostrado la presencia y supervivencia de Candida albicans hasta por dos semanas en cepillos dentales de portadores sanos; ${ }^{3}$ igualmente, cepillos contaminados con bacilos entéricos Gram (-) causantes de enfermedad periodontal fueron analizados demostrándose la resistencia a la acción antibacterial de la crema dental. ${ }^{1,3}$ Streptococcus mutans, bacteria común en dientes con caries dental ha sido aislado de cepillos dentales y tratado con clorhexidina al $0,12 \%$ como propuesta para evitar la auto-inoculación cada vez que se realiza el cepillado dental. ${ }^{3}$

En la cavidad bucal de un individuo sano se puede encontrar una microflora oral muy variada. Se considera que existen más de 400 especies de las cuales no todas han sido aisladas y estudiadas. ${ }^{4}$

Los microorganismos llegan a cavidad bucal de fuentes tales como: el medio ambiente, los dedos de la persona, el aerosol emanado del sanitario (siendo los antiguos sanitarios los más contaminantes por el mayor volumen de descarga y por lo tanto mayor posibilidad de aerolizaciòn y contaminación), sitios húmedos del cuarto de baño, uso prolongado del cepillo que incrementa el número de microorganismos en sus penachos, re-contaminación con otros cepillos almacenados adyacentemente o con el aerosol de los sanitarios sin tapa. ${ }^{5-7}$ También, se ha reportado que la protección plástica que se puede colocar al cepillo dental puede ocasionar el crecimiento de microorganismos oportunistas como Pseudomona aeruginosa. $^{5}$
Científicamente se ha comprobado que cuando aumenta la concentración de microorganismos en la saliva se producen enfermedades como estomatitis aftosa recurrente, glositis migratoria, glosopirosis, caries y enfermedad periodontal. ${ }^{5,8}$ Estas patologías se podrían evitar al tener hábitos de recambio adecuado del cepillo dental y un buen almacenamiento y mantenimiento del mismo. ${ }^{9,10}$

Es importante que las personas conozcan las consecuencias de un almacenamiento y mantenimiento inadecuado del cepillo dental ya que éste juega un papel importante como ventana de entrada a enfermedades sistémicas.

Crear y aplicar un material educativo como medida preventiva de salud publica sobre la forma de limpiar, almacenar y hacer el recambio del cepillo dental posibilita la disminución de riesgo de contaminación bacteriana y previene el riesgo de adquirir enfermedades. El objetivo de este estudo fue evaluar los aspectos relacionados con el almacenamiento y el mantenimiento del cepillo dental, antes y después de aplicado un material educativo.

\section{MATERIALES Y MÉTODOS}

Se realizó un ensayo clínico controlado, la población estuvo conformada por 100 sujetos que acudieron a las Clínicas Odontológicas de la Universidad Santo Tomás (Bucaramanga) durante el segundo semestre de 2008 , con edades entre los 18 y 40 años. Se realizo un muestreo no probabilístico, los participantes se seleccionaron por conveniencia. ${ }^{5}$

\section{Criterios de inclusión y exclusión:}

Fueron incluidos los pacientes entre los 18 y 40 años que gozaban de buena salud mental; condiciones de visión, audición y comunicación consideradas normales que aceptaron participar en el estudio y que ejecutaban por lo menos un cepillado diario.

Se excluyeron los pacientes que vivían en condiciones de hacinamiento o sufrían los problemas de desplazamiento forzado, que estaban en planes de traslado próximo del lugar de residencia y/o con condición mental comprometida pérdida de la visión, audición o el habla.

\section{Variables}

Se consideraron variables sociodemográficas como edad, género, estrato.

Variables de uso de cepillo dental e higiene como utiliza crema, frecuencia de uso del cepillo dental, recambio del cepillo dental, posición del cepillo en el baño, cepillos para su uso, almacenamiento, sitio de almacenamiento dentro del baño, sitio de alma- 
cenamiento fuera del baño, distancia del cepillo al sanitario, métodos de desinfección, residuos de comida en cerdas.

Variable cuarto de baño como tipo de baños, presencia de tapa, baja la tapa.

Variable de información sobre la contaminación del cepillo dental como bajar la tapa del sanitario, cercanía de los cepillos dentales.

\section{Procedimiento}

Se elaboro un instrumento con tres aspectos báscios para evaluar el material educativo. Se realizó un programa de entrenamiento y una prueba piloto en diez pacientes que acudieron a las Clínicas Odontológicas con el fin de estandarizar la evaluación, evaluar la factibilidad y determinar posibles inconvenientes. Se diseñó y elaboró un folleto ilustrado didáctico titulado "El cepillo dental ¿Tú dónde lo guardas?" (Figura 1).

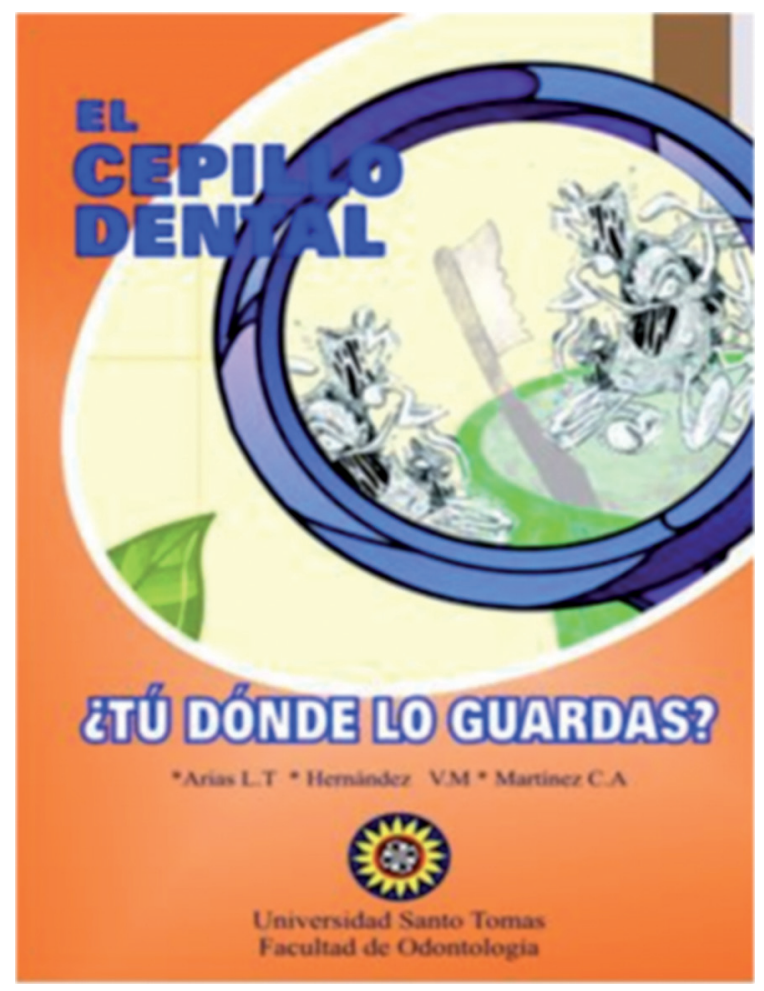

Figura 1. Material educativo realizado para el estudio.

Se efectuaron las llamadas telefónicas para corroborar la información de la residencia de los pacientes seleccionados para el estudio. Se solicitó el permiso para visitar sus hogares, de acuerdo con los criterios de inclusión, y se constituyo al azar un grupo control y un grupo intervenido.

Se efectúo una visita a cada uno de los hogares. Se diligenció la primera parte del instrumento a los dos grupos, en el cual se inspeccionaron las condiciones en las que se encontraron los cepillos dentales; esto lo realizó el encuestador, mediante una observación y bajo los criterios preestablecidos. En el mismo día se entregó el folleto a los encuestados pertenecientes al grupo intervenido, se les dieron explicaciones e instrucciones del contenido y objetivo del folleto.

La segunda visita se realizó 15 días después, sin previo aviso. Se hizo una nueva entrevista para lo cual se utilizo la segunda parte del instrumento. El grupo control, se entrevisto en el mismo lapso de tiempo, se le aplicó la segunda parte del instrumento igual que al grupo intervenido.

La base de datos se elaboró en el programa Excel por duplicado y se exportó al programa Epi-Info 6.04 mediante la rutina validate. ${ }^{11,12}$ Después que se duplicó la calidad de la digitación, se exportó al paquete Stata 9.0 para su análisis definitivo. ${ }^{13}$

\section{Análisis de los datos}

Inicialmente, se considero un análisis univariado en el que cada variable se describió según las medidas de resumen, según la naturaleza de su variable; para las cualitativas, se calcularon las proporciones. Para las cuantitativas, se obtuvieron medidas de tendencia central como la media, mediana y de dispersión como rango, desviación estándar.

En el análisis bivariado considerado como variable de salida, intervención si / no, la cual se analizó con cada una de las variables por medio del test de $\mathrm{Chi}^{2}$ o Test Exacto de Fisher, para las variables cualitativas y para las cuantitativas t de Student, rango de Wilconxon o test de Mann Whithey según la distribución de los datos. Se considero un nivel de significancia de $\alpha: 0.05 .14,15$

\section{Consideraciones éticas}

Basados en las recomendaciones éticas establecidas en la resolución 008430 de 1993 del Ministerio de Protección Social de la República de Colombia y en la Declaración de Helsinky de 1975, se recibió autorización del Comité de Ética Institucional. En todos los casos se obtuvo un consentimiento informado, se garantizó la privacidad y la no divulgación de información y datos recopilados durante el estudio. Igualmente, se cumplió con el principio de beneficio a los individuos que participaron en el estudio y en igualdad de condiciones. No se realizó ningún tipo de práctica que pudiera agredir la integridad y salud de los investigados. ${ }^{16}$

\section{RESULTADOS}

Los resultados señalaron que la frecuencia de uso diario de cepillo dental del total de la población es 
de 2.9 veces al día, realizan recambio de cepillo cada 5.4 meses, y la mayoría tiene un sólo cepillo dental en uso (Tabla 1).

Antes de realizar la aplicación del material educativo, 41 individuos no bajaban la tapa del baño al momento de la descarga; de estos 41, 19 (46.3 pertenecian al grupo no intervenido con un $\mathrm{p}=0.26$ ). El $99 \%$ no utilizaban métodos desinfectantes para el cepillo dental, de éstos el $50.1 \%$ correspondía al grupo no intervenido $(\mathrm{p}=<0.001)$ (Tabla 1$)$.

El cepillo dental era almacenado individualmente por el 31\% de los pacientes de los cuales el $64.5 \%$ pertenecian al grupo intervenido. El sanitario era de alta descarga de agua en el $81 \%$ de los hogares correspondiendo a éstos el $56 \%$ del grupo no intervenido con un valor estadísticamente significativo $(p=0.02)$ con respecto al grupo intervenido. Cincuenta y dos sanitarios no tienen tapa (53\% del grupo no intervenido y $46.1 \%$ del intervenido). La distancia promedio del sanitario al alcance del sitio de almacenamiento del cepillo dental era de 144 $\pm 48 \mathrm{~cm}$ para el grupo no intervenido y de $117.8 \pm$ $27 \mathrm{~cm}$ para el grupo intervenido (Tabla 1).

Al revisar macroscópicamente el estado del cepillo dental, se encontró presencia de placa dentobacteriana en el 68\% de los cepillos; de éstos, el 62\% correspondían al grupo no intervenido (Tabla 1 ).

Tabla 1. Descripción de aspectos observados en los cuartos de baño y su uso, antes y después de la intervención.

\begin{tabular}{|c|c|c|c|c|c|c|c|c|}
\hline \multirow[b]{2}{*}{ Variable } & \multirow[b]{2}{*}{$\begin{array}{c}\text { Global } \\
\text { n (\%) }\end{array}$} & \multicolumn{2}{|c|}{ ANTES } & \multirow[b]{2}{*}{$\mathbf{P}^{*}$} & \multirow[b]{2}{*}{$\begin{array}{c}\text { Global } \\
\text { n (\%) }\end{array}$} & \multicolumn{2}{|c|}{ DESPUÉS } & \multirow[b]{2}{*}{$\mathbf{p}^{*}$} \\
\hline & & $\begin{array}{c}\text { Control } \\
\text { n (\%) }\end{array}$ & $\begin{array}{c}\text { Intervenido } \\
\mathbf{n}(\%)\end{array}$ & & & $\begin{array}{c}\text { Control } \\
\text { n (\%) }\end{array}$ & $\begin{array}{c}\text { Intervenido } \\
\text { n (\%) }\end{array}$ & \\
\hline \multicolumn{9}{|l|}{$\begin{array}{l}\text { Baño que } \\
\text { utiliza }\end{array}$} \\
\hline Alta descarga & $81(81)$ & $45(56)$ & $36(44)$ & 0.02 & $80(80)$ & $45(56.2)$ & $35(44)$ & 0.012 \\
\hline Baja descarga & $19(19)$ & $5(26.3)$ & $14(74)$ & & $20(20)$ & $5(25)$ & $15(75)$ & \\
\hline \multicolumn{9}{|l|}{$\begin{array}{l}\text { Presencia de } \\
\text { tapa }\end{array}$} \\
\hline No & $52(52)$ & $28(53.9)$ & $24(46.1)$ & 0.42 & $49(49)$ & $28(57.1)$ & 21 (42.9) & 0.16 \\
\hline $\mathrm{Si}$ & $48(48)$ & $22(46)$ & $26(54)$ & & $51(51)$ & $22(43.1)$ & 29 (56.9) & \\
\hline \multicolumn{9}{|l|}{$\begin{array}{l}\text { Baja la tapa } \\
\text { de sanitario }\end{array}$} \\
\hline No & $41(41)$ & $19(46.3)$ & $22(53.6)$ & 0.26 & $30(30)$ & 19 (63.3) & $11(36.7)$ & 0.004 \\
\hline $\mathrm{Si}$ & $10(10)$ & $3(30)$ & $7(70)$ & & $18(18)$ & $13(17)$ & $15(83)$ & \\
\hline No aplica & 49 (49) & $28(57)$ & 21 (42.9) & & $52(52)$ & 28 (53.9) & $24(46.1)$ & \\
\hline $\begin{array}{l}\text { Distancia del } \\
\text { sanitario } \\
\text { al cepillo }\end{array}$ & $131 \pm 49$ & $144 \pm 61$ & $117.8 \pm 27.6$ & 0.006 & $144 \pm 48$ & $144 \pm 61$ & $144 \pm 31$ & 0.94 \\
\hline
\end{tabular}

El 85\% de los pacientes guardaban el cepillo principal dentro del baño, el 67\% de ellos, no utilizaban algún tipo de protección. De los que cubrían de alguna manera el cepillo, el $72.2 \%$ correspondió al grupo intervenido y el $27.7 \%$ al no intervenido $(p=$ $0.016)$. De los pacientes que guardaban el cepillo fuera del baño, 5 (71.4\%) correspondientes todos al grupo intervenido lo protegían y cinco del mismo grupo no utilizaban ningún medio de protección (Tabla 2).

Después de realizada la aplicación del material educativo, se reporto que de los pacientes que guarda- ban el cepillo en forma individual, el $70.2 \%$ correspondió al grupo intervenido. Valor estadísticamente significativo $(p=0.001)$ frente al $30 \%$ del grupo no intervenido. Respecto al uso de desinfección, paso de $1 \%$ al $26 \%$ después de la intervención, $100 \%$ de éstos habían sido intervenidos con la estrategia educativa $(\mathrm{p}<0.001)$ (Tabla 2$)$.

No hubo cambios significativos en cuanto a la antigüedad del sanitario. Los sanitarios eran antiguos 0 de alta descarga de agua en un $80 \%$, de estos el $44 \%$ pertenecían al grupo intervenido. No tenía tapa la mitad de las tazas de baño lo que conrespondía al 
$57.1 \%$ del grupo no intervenido. Al revisar detenidamente los cepillos se encontró que el 50\% no tenían placa y de estos, el 66\% correspondió al grupo intervenido ( $p=0.001$ ) (Tabla 2 ).

El cepillo principal se mantenía dentro del baño en el $62 \%$ de los encuestados, sólo el $27.4 \%$ pertenecían al grupo intervenido. El $83 \%$ de los que deja- ban el cepillo dentro del baño sin protección, pertenecían al grupo control y el $16 \%$ al grupo intervenido $(p=0.003)$. De 38 que dejaban su cepillo fuera del baño, 33 (87\%) pertenecían al grupo intervenido con una significancia de $\mathrm{p}=0.001$. De los pacientes que guardaban el cepillo fuera del baño, 14 (87.5\%) del grupo intervenido lo cubrían con algún tipo de protección (Tabla 2).

Tabla 2. Descripción de aspectos observados referentes al almacenamiento y mantenimiento del cepillo dental antes y después de la intervención.

\begin{tabular}{|c|c|c|c|c|c|c|c|c|}
\hline \multirow[b]{2}{*}{ Variable } & \multirow[b]{2}{*}{ Global } & \multicolumn{2}{|c|}{ ANTES } & \multirow[b]{2}{*}{$\mathbf{p}^{*}$} & \multirow[b]{2}{*}{ Global } & \multicolumn{2}{|c|}{ DESPUÉS } & \multirow[b]{2}{*}{$\mathbf{p}^{*}$} \\
\hline & & $\begin{array}{l}\text { Control } \\
\text { n (\%) }\end{array}$ & $\begin{array}{c}\text { Intervenido } \\
\mathbf{n}(\%)\end{array}$ & & & $\begin{array}{c}\text { Control } \\
\text { n (\%) }\end{array}$ & $\begin{array}{l}\text { Intervenido } \\
\text { n (\%) }\end{array}$ & \\
\hline $\begin{array}{l}\text { Uso diario del } \\
\text { cepillo }\end{array}$ & $2.9 \pm 0.6$ & $3 \pm 0.5$ & $2.7 \pm 0.6$ & 0.01 & & & & \\
\hline $\begin{array}{l}\text { Cambio del } \\
\text { cepillo (meses) }\end{array}$ & $5.4 \pm 1.6$ & $6.0 \pm 1.5$ & $4.8 \pm 1$ & 0.8 & & & & \\
\hline $\begin{array}{l}\text { Cepillos para } \\
\text { su uso }\end{array}$ & $1.1 \pm 0.4$ & $1.1 \pm 0.4$ & $1.2 \pm 0.4$ & 0.66 & $1.19 \pm 0.4$ & $1.16 \pm 0.4$ & $1.22 \pm 0.4$ & 0.52 \\
\hline \multicolumn{9}{|l|}{$\begin{array}{l}\text { Residuos en } \\
\text { cepillo }\end{array}$} \\
\hline No & $32(32)$ & $8(25)$ & $24(75)$ & 0.001 & $50(50)$ & $17(34)$ & $33(66)$ & 0.001 \\
\hline $\mathrm{Si}$ & $68(68)$ & $42(62)$ & $26(38)$ & & $50(50)$ & $33(66)$ & $17(34)$ & \\
\hline \multicolumn{9}{|l|}{$\begin{array}{l}\text { Método de } \\
\text { desinfección }\end{array}$} \\
\hline No utiliza & $99(99)$ & $50(50)$ & $49(49)$ & 1.0 & $74(74)$ & $50(68)$ & $24(32)$ & $<0.001$ \\
\hline Si utiliza & $1(1)$ & -- & $1(100)$ & & $26(26)$ & --- & $26(100)$ & \\
\hline \multicolumn{9}{|l|}{$\begin{array}{l}\text { Forma en que } \\
\text { deja su cepillo }\end{array}$} \\
\hline Solo & $31(31)$ & $11(35.4)$ & $20(64.5)$ & 0.05 & $47(47)$ & $14(30)$ & $33(70)$ & $<0.001$ \\
\hline $\begin{array}{l}\text { En conjunto } \\
\text { Dónde deja su } \\
\text { cepillo }\end{array}$ & $69(69)$ & 39 (56.5) & $30(43.4)$ & & $53(53)$ & $36(68)$ & $17(32)$ & \\
\hline Dentro el baño & $85(85)$ & $45(53)$ & $40(47)$ & 0.16 & $62(62)$ & $45(73)$ & $17(27)$ & $<0.001$ \\
\hline Fuera del baño & $15(15)$ & $5(33.3)$ & $10(67)$ & & $38(38)$ & $5(13.2)$ & $33(87)$ & \\
\hline $\begin{array}{l}\text { Dentro } \\
\text { protección }\end{array}$ & $18(18)$ & $5(27.7)$ & $13(72)$ & $0.016 \neq$ & $12(12)$ & $5(41.6)$ & $7(58)$ & $<0.003$ \\
\hline $\begin{array}{l}\text { Dentro sin } \\
\text { protección }\end{array}$ & $67(67)$ & $40(60)$ & $27(40)$ & & $48(48)$ & $40(83)$ & $8(16.6)$ & \\
\hline NA & & & & & $2(2)$ & & $2(100)$ & \\
\hline $\begin{array}{l}\text { Fuera con } \\
\text { protección }\end{array}$ & $7(7)$ & $2(28.5)$ & $5(71.4)$ & $0.194^{*}$ & $16(16)$ & $2(12.5)$ & 14 (87.5) & $1^{*}$ \\
\hline $\begin{array}{l}\text { Fuera sin } \\
\text { protección }\end{array}$ & $8(8)$ & $3(37.5)$ & $5(62.5)$ & & $22(22)$ & $3(13.6)$ & $19(86.3)$ & \\
\hline
\end{tabular}

$\mathrm{n}=100 \quad *$ Test Exacto de Fischer $\quad \neq \mathrm{Chi}^{2}$

\section{DISCUSIÓN}

Es poca la población que reconoce que el aerosol producido por la descarga del sanitario lleva bacterias a diferentes sitios del cuarto de baño las cuales pueden depositarse en los utensilios que se encuentren en un perímetro de $108 \mathrm{~cm}$ y contaminarlos haciendo posible la adquisición 
de patologías. ${ }^{8}$ La importancia que hoy en día se da a la asociación de enfermedades sistémicas, especialmente las cardiovasculares con la cavidad bucal nos lleva a implementar medidas de promoción y prevención. Por ello, el objetivo del estudio fue evaluar los hábitos de higiene y mantenimiento del cepillo dental, antes y después de la aplicación de un material educativo orientado a promover la higiene y mantenimiento adecuados del cepillo dental y su entorno.

La frecuencia de cepillado se considera un factor importante relacionado con la salud bucal. Se han reportado estudios en diferentes grupos sobre el tema. Un estudio realizado sobre los hábitos de higiene bucal y su efecto sobre la salud dental en niños de 6 y 7 años confirmó que el cepillado tres veces al día fue el más frecuente. De 123 escolares de entre 7 y 13 años evaluados por encuestas personales domiciliarias realizadas a los padres de los escolares en Navarra, señalo que el 55,3\% se cepillaban dos o tres veces al día. De 899 adultos que fueron encuestados telefónicamente, un $64,7 \%$ afirmaron cepillarse los dientes después de cada comida y solamente el $29,3 \%$ declaró cepillarse una sola vez al día. ${ }^{7}$ Estos datos son similares a los obtenidos mediante la encuesta a los pacientes de clínicas de la USTA quienes reportaron una frecuencia de cepillado diario de 2.9

De acuerdo con varios estudios, se ha sugerido que los cepillos dentales suelen portar cantidades importantes de microorganismos que pueden pasar de un cepillo a otro y generar reinfecciones y contaminación cruzada. Actualmente, se indica el cambio del cepillo dental cada mes; sin embargo, el recambio que se genera en la población estudiada es de 5.4 meses tiempo muy amplio que permite el acumulo de bacterias y la reinfección por las mismas. ${ }^{1,27,9,10,17,18}$

No se encontraron muchos estudios que muestren el uso o no de desinfectantes del cepillo dental; sin embargo, se han sugerido algunas sustancias como hipoclorito de sodio o clorhexidina. ${ }^{4}$ Este estudio reporto que los encuestados lavan el cepillo con chorro de agua y no utilizaban ningún método de desinfección antes de la intervención educativa pero demostraron cambios después de ella.

La existencia de contaminación cruzada de bacterias aerobias entre cepillos cuando éstos eran almacenados en el mismo lugar, se verifico por Gonzáles y colaboradores. En su estudio, se evaluaron 30 personas a las cuales se les hizo análisis bacteriológico de cavidad bucal previo y se les entregaron dos cepillos nuevos, al mes se recogieron los cepillos y se realizo la segunda parte del estudio que consistía verificar la presencia de bacterias y la posibilidad de infección cruzada. El cepillo resulto ser un reservorio de bacterias presentes en cavidad bucal y la cercanía entre los cepillos permitió la contaminación cruzada entre los mismos. ${ }^{19}$ Un factor importante que contribuye es la inadecuada limpieza que se da al cepillo y el ambiente húmedo donde generalmente permanece. ${ }^{20}$

Díaz y colaboradores realizaron un estudio en 150 baños seleccionados de manera aleatoria en la ciudad de Cartagena; se pretendía analizar la distancia a la que normalmente se guarda el cepillo con respecto a otro. Se encontró que la mayoría de población dejaba su cepillo en conjunto con otros a una distancia promedio de $2 \mathrm{~cm} .^{8}$ En este estudio, se observó que el $69 \%$ de los encuestados dejaban su cepillo dental en compañía de otros cepillos muy cercanos a la distancia descrita por Díaz y colaboradores.

Así mismo, Díaz y colaboradores concluyeron que la distancia de salpicadura máxima del aerosol emitido por la descarga del sanitario se detectó a $145 \mathrm{~cm}$; los cepillos se guardaban dentro del baño en un $87.32 \%$ y la distancia promedio de la ubicación del cepillero respecto al servicio de sanitario fue de $108 \mathrm{~cm}$, el $87.25 \%$ de los inodoros eran viejos o de alta descarga de agua. ${ }^{8}$

Cabe aclarar que los datos encontrados al revisar los cuartos de baño en la primera visita domiciliaría a los pacientes de las clínicas de la Universidad Santo Tomás fueron muy similares pues se observo una distancia de cepillero respecto al servicio de sanitario de $131 \mathrm{~cm}$; el 85\% de los cepillos se guardaban dentro del cuarto de baño, lo cual indica que se encuentran dentro del área de salpicadura. Además, el $81 \%$ de los inodoros eran antiguos.

Después de realizada la segunda visita a los hogares encuestados se determinó que el 74\% no creyó importante utilizar algún método de desinfección, mientras que el 52\% no tenia tapa a la hora de hacer la descarga del sanitario. Cabe anotar que la visita se realizo 15 días después de la entrega de material educativo al grupo intervenido y se considero que es un lapso de tiempo muy corto para que se tomen medidas tales como colocar tapa al sanitario y menos de renovarlo si se considera que el modelo era antiguo. Por tanto, los resultados que tienen que ver con la infraestructura del cuarto de baño siguen siendo los mismos que antes de la intervención. Sin embargo, se generaron cambios muy satisfactorios de hábitos de almacenamiento y mantenimiento del cepillo dental en el grupo intervenido. Después de realizada la intervención, el $87 \%$ del grupo intervenido y el $13 \%$ del grupo control guardaban su cepillo principal fuera del baño, de estos el 16\% del grupo intervenido y el $84 \%$ del grupo control guardaban el cepillo dental sin protección.

Después de conocer el manual "El cepillo dental ¿Tú dónde lo guardas?" el grupo intervenido fue evaluado 
acerca de los conocimientos adquiridos y sobre el material educativo. Los resultados fueron los esperados ya que el $94 \%$ (47) del grupo intervenido manifestaron que el material era muy interesante y el $92 \%$ (46) no sugirió hacer cambios al manual.

\section{CONCLUSIONES}

Los resultados de la primera encuesta mostraron muy poco conocimiento acerca de la contaminación bacteriana presente en los cepillos dentales al exponerse en los cuartos de baño.

Al implementar el manual educativo "El cepillo dental ¿Tú dónde lo guardas?" en el grupo intervenido, los resultados de la segunda encuesta, mostraron que la mayoría de la población cambió los hábitos de almacenamiento y mantenimiento del cepillo dental lo que sugiere que la elaboración y la implementación de dicho material tuvo impacto en la población intervenida.

Se logró mejorar el cuidado del cepillo dental en cuanto a desinfección y almacenamiento adecuado

\section{Agradecimientos.}

A la Universidad Santo Tomás, Bucaramanga por la reproducción del material educativo utilizado y la financiación del proyecto.

\section{BIBLIOGRAFÍA}

1. Contareis A, Astudillo M, Daza LH, García LM, Gaviria P, Rosales H, Parra B, Jaramillo A. Contaminación microbiana de los cepillos dentales en pacientes con enfermedad periodontal. Revista Estomatología [en línea] 2002; 10: 4 - 14 [fecha de acceso: junio de 2006] URL disponible en: http://odontologia.univalle.edu.co/estomatologia/publicaciones/vol10num$1 \mathrm{mar2002pre.htm}$

2. Taji SS, Rogers AH. The microbial contamination of toothbrushes. A pilot study. Aust Dent J 1998; 43: $128-130$.

3. Turner JE, Moore DW, Shaw, BS. Prevalence and antibiotic susceptibility of organisms isolated from acute soft tissue abscesses secondary to dental caries. Oral Surg Oral Med Oral Pathol Oral Radiol Endod 1975; 39: 848 - 857.

4. Herrera H, Herrera H, Chávez A. Gluconato de Clorhexidina al $0,12 \%$ como estrategia preventiva para evitar la reinoculación de Streptococcus mutans presentes en cepillos dentales, y biberones. Crea Ciencia 2005; 2 : $45-50$.

5. Liébana UJ. Microbiología Oral. Mexico D.F: Editorial McGraw-Hill Interamericana,1997.

6. Marcano C. El cepillo de dientes en la ecología de Candida albicans. Instituto de Medicina Tropical, Seccion de Micologia Médica, Universidad Central de Venezuela, Mycopathologia 1981; 74: 135-141.

7. Contreras A, Arce RM, Botero JE, Jaramillo A, Con- taminación bacteriana de cepillos dentales en niños y sus padres: una cuestión de educación. Revista Estomatología [en línea] 2002; 10: 1 - 10. [fecha de acceso: junio de 2006] URL disponible en: http:// odontologia.univalle.edu.co/estomatologia/publicaciones/vol10num 1 mar2002pre.htm

8. Díaz AJ, León EE, Montoya ME, Vivero LE, Abello RE. Evaluación del área de salpicadura máxima de la descarga de los inodoros y su relación con la ubicación de los cepillos dentales en cuartos de baños en barrios de Cartagena, Colombia. Univ Odontol 2002; 47: 31 - 36 .

9. Abhishek M, Sequeira P, Gopalkrishna B. Bacterial contamination and decontamination of toothbrushes after use. N Y State Dent J 2007; 73: 20 - 22.

10. Gaviria P, Rosales H, Contreras A. Contaminación in vitro de cepillos dentales. Revista Estomatología [en línea] 2001; 9: $14-20$. [fecha de acceso: junio de 2006] URL disponible en: http://odontologia.univalle.edu.co/estomatologia/publicaciones/vol10num$1 \mathrm{mar2002pre.htm}$

11. Microsoft Corporation 1998. Microsoft Excel 5.0.

12. Dean AG, Dean JA, Coulumbier D, Brendel KA, Smith DC, Burton AH, et al. Epi Info6, version 6.04: a word processing, database, and statistics program for epidemiology on microcomputers. Atlanta: Centers for Disease Control and Prevention; 1996.

13. Stata Corporation 2003. Stata Statistical Software release 8.0 college station, $\mathrm{t}-\mathrm{x}$.

14. Mata P, Arizmendi F, Salazar A. Conceptos básicos de estadística descriptiva útiles para el médico. Rev Hosp Gral Dr. M Gea González 2006; 7: 42 - 46.

15. Savitz DA, Tolo KA, Poole C. Statistical significance testing in the American Journal of Epidemiology, 1970 - 1990. Am J Epidemiol 1994; 139: 1047 - 1052.

16. República de Colombia, Ministerio de Salud. Resolución No 008430 DE 1993 Ley (53) de 1992. Normas científicas, técnicas y administrativas para la investigación en salud. [en línea]. URL disponible en: http://www.urosario.edu.co/medicina/documentos/facultades/medicina/investigaciones/resolucion_008430_1993.pdf

17. Manau C, Zabalegui I, Noguerol B, Liodra JC, Rebelo $\mathrm{H}$, Echevarría JJ et al. Control de placa e higiene bucodental: Resumen de los resultados del 1er. Workshop Ibérico. RCOE [en línea]. 2004; 9: 215 - 223. URL disponible en: http://scielo.isciii. es/scielo.php? script $=$ sci arttext $\&$ pid $=$ S 1138 $123 \times 2004000200006 \& \operatorname{lng}=\overline{\mathrm{s}}$.

18. Bunetel L, Tricot Doleux S, Agnani G, Bonnaure-Mallet $M$. In vitro evaluation of the retention of three species of pathogenic microorganism by three different types of toothbrush. Oral Microbiol Immunol 2000;15: 313 - 316 .

19. Gonzales I, Fortich-Meza N. Contaminación de cepillos dentales y su relación con caries dental y enfermedad periodontal en los estudiantes de Clínica del Sano I y II de la Facultad de Odontología de la CURN Colombia, Memorias VIII Encuentro de Semilleros de Investigación ACFO, Colombia Ed. Corporación Universitaria Rafael Núñez 2008: 68 - 78.

20. Efstratiou M, Papaioannou W, Nakou M, Ktenas E, Vrotsos IA, Panis V. Contamination of a toothbrush with antibacterial properties by oral microorganisms. J Dent 2007; 35: 331 - 337. 